\title{
Development of disease-resistant rice using regulatory components of induced disease resistance
}

\author{
Hiroshi Takatsuji* \\ Disease Resistant Crops Research Unit, Genetically Modified Organism Research Center, National Institute of Agrobiological Sciences, Tsukuba, Japan
}

\section{Edited by:}

Seiichi Toki, National Institute of Agrobiological Sciences, Japan

\section{Reviewed by:}

Masaru Ohme-Takagi, National Institute of Advanced Industrial Science and Technology, Japan David De Vleesschauwer, Ghent University, Belgium

\section{*Correspondence:}

Hiroshi Takatsuji, Disease Resistant Crops Research Unit, Genetically Modified Organism Research Center National Institute of Agrobiological

Sciences, 2-1-2 Kannondai, Tsukuba 305-8602, Japan

e-mail: takatsuh@affrc.go.jp
Infectious diseases cause huge crop losses annually. In response to pathogen attacks, plants activate defense systems that are mediated through various signaling pathways. The salicylic acid (SA) signaling pathway is the most powerful of these pathways. Several regulatory components of the SA signaling pathway have been identified, and are potential targets for genetic manipulation of plants' disease resistance. However, the resistance associated with these regulatory components is often accompanied by fitness costs; that is, negative effects on plant growth and crop yield. Chemical defense inducers, such as benzothiadiazole and probenazole, act on the SA pathway and induce strong resistance to various pathogens without major fitness costs, owing to their 'priming effect.' Studies on how benzothiadiazole induces disease resistance in rice have identified WRKY45, a key transcription factor in the branched SA pathway, and OsNPR1/NH1. Rice plants overexpressing WRKY45 were extremely resistant to rice blast disease caused by the fungus Magnaporthe oryzae and bacterial leaf blight disease caused by Xanthomonas oryzae pv. oryzae (Xoo), the two major rice diseases. Disease resistance is often accompanied by fitness costs; however, WRKY45 overexpression imposed relatively small fitness costs on rice because of its priming effect. This priming effect was similar to that of chemical defense inducers, although the fitness costs were amplified by some environmental factors. WRKY45 is degraded by the ubiquitin-proteasome system, and the dual role of this degradation partly explains the priming effect. The synergistic interaction between SA and cytokinin signaling that activates WRKY45 also likely contributes to the priming effect. With a main focus on these studies, I review the current knowledge of SApathway-dependent defense in rice by comparing it with that in Arabidopsis, and discuss potential strategies to develop disease-resistant rice using signaling components.

Keywords: rice, Magnaporthe oryzae, Xanthomonas oryzae pv. Oryzae, chemical defense inducer, priming effect, WRKY45, NPR1, tradeoff

\section{INTRODUCTION}

In nature, plants are continuously threatened by a wide range of pathogens. To prevent pathogen invasion, plants have evolved an array of structural barriers and preformed antimicrobial metabolites. They have also evolved a broad spectrum of inducible defense strategies to translate the perception of attackers into effective immune responses. The sensing of pathogen-associated molecular patterns (PAMPs) by pattern recognition receptors (PRRs) initiates PAMP-triggered immunity (PTI), which prevents pathogen colonization (Nurnberger et al., 2004; Ausubel, 2005; Boller and He, 2009; Zipfel, 2009; Schwessinger and Ronald, 2012). As a second layer of induced defense in plants, resistance (R) proteins recognize effector proteins secreted by microbial pathogens, and trigger strong disease-resistance responses. Among these responses is effector-triggered immunity (ETI), which is usually associated with hypersensitive responses (HR) characterized by rapid programmed cell death at the sites of infection (Jones and Dangl, 2006; Dodds and Rathjen, 2010; Spoel and Dong, 2012). Multiple signaling pathways, including those mediated by salicylic acid (SA), jasmonic acid (JA), and ethylene are involved in transducing the signal of pathogen perception into an immune response.
Rice is the staple food for more than half of the world's population, as well as being a model monocot species for plant research. It has been proposed that rice production must increase by more than $40 \%$ by 2030 to meet the increasing demand (Khush, 2005). To overcome this challenge, it is particularly important to develop high-yielding rice lines that are tolerant to biotic and abiotic stresses. Infectious diseases are among the most serious threats to crop production. A previous study estimated that infectious diseases cause losses of up to $40 \%$ in rice production annually (Oerke and Dehne, 2004). Blast disease, caused by the fungus Magnaporthe oryzae, and leaf-blight disease, caused by the bacteria Xanthomonas oryzae pv. oryzae (Xoo), are among the most serious and widespread diseases of cultivated rice, and continuously threaten rice production worldwide $(\mathrm{Ou}, 1987$; Gnanamanickam et al., 1999).

Agrochemicals have greatly increased rice production in some regions, although their expense has prevented their wide-spread use globally. Rice breeders have attempted to use genes encoding $\mathrm{R}$ proteins ( $R$ genes) to introduce ETI against specific rice diseases into rice cultivars (Zhang, 2007). However, race specificity and the 
potential risks of resistance breakdown have limited the versatility of R-gene-dependent disease resistance (Bonman et al., 1992). More recently, breeders have introduced field resistance genes into rice to improve resistance to diseases such as blast. This type of resistance is durable and non-race-specific (Miah et al., 2013).

Recent advances in research on plant-pathogen interactions have provided insights into the mechanisms of plants' defenses against potential pathogens. Such studies have identified a number of signaling molecules, such as protein kinases and transcription factors (TFs), that mediate the translation of pathogen perception into defense responses (Delteil et al., 2010). Using the components of such defense mechanisms, it is now possible to develop new strategies to produce disease-resistant rice cultivars. One strategy is to modify the defense signaling pathways by transgenic manipulation of the genes encoding defense-related signaling molecules. The regulatory components in the SA signaling pathway are particularly important, because this pathway leads to strong disease resistance. However, simple overexpression or knockout (knockdown) of the genes encoding positive and negative regulators of the signaling pathway, respectively, have often resulted in negative effects on plant growth and yield. These negative effects, the 'fitness costs,' represent the price of strong disease resistance as resources are reallocated from growth to defense. Such tradeoffs also exist between biotic and abiotic stress responses in plants (Matyssek et al., 2005; Sharma et al., 2013).

Crosstalks among different signaling pathways are thought to be involved in the tradeoffs between resistance and growth and between biotic and abiotic stress resistance. Thus, when selecting genes for developing disease-resistant rice, it is important to consider not only their defense-related functions, but also their roles in plant growth and/or abiotic stress responses. It is also important to drive expression of the selected genes in a manner consistent with their function. In this article, I review recent progress in the identification and characterization of the regulatory components in the rice SA pathway. I also discuss their potential uses for developing disease-resistant rice lines using transgenic approaches, with a focus on avoiding the problems associated with tradeoffs.

\section{SALICYLIC ACID SIGNALING PATHWAY COMPONENTS AS TARGETS FOR PLANT PROTECTION AGAINST DISEASES}

The importance of the SA-dependent signaling pathway in plant defense against pathogens was initially recognized in studies on systemic acquired resistance (SAR) in dicots. Pathogen infection often induces SA accumulation in infected leaves of various plant species, and SA also accumulates in distal leaves that develop SAR (Malamy etal., 1990; Métraux et al., 1990). Blocking SA accumulation by expressing an SA-degrading enzyme abolished SAR in transgenic tobacco and Arabidopsis (Gaffney et al., 1993; Delaney et al., 1995). Mutations in SA biosynthetic genes enhanced plant susceptibility to pathogens, and application of SA to the mutants restored their resistance (Mauch-Mani and Slusarenko, 1996; Nawrath and Metraux, 1999; Wildermuth et al., 2001). These results and observations indicate that the SA signaling pathway plays a crucial role in the defense mechanisms of plants. Both PTI and ETI induce SAR (Tsuda et al., 2009). In dicots, SA-pathwaydependent defense is effective against biotrophic pathogens, but not necrotrophic pathogens (Glazebrook, 2005).
Application of functional SA analogs, such as 2,6dichloroisonicotinic acid (INA), benzothiadiazole $S$-methyl ester (BTH), and probenazole activate the expression of $P R$ genes, leading to resistance against viral, bacterial, oomycete, and fungal pathogens. This chemical-induced resistance has been observed in several dicots (Malamy etal., 1990; Métraux etal., 1991; Lawton et al., 1996; Yoshioka et al., 2001) and monocots (Iwata et al., 1980; Görlach et al., 1996; Pasquer et al., 2005; Makandar etal., 2006; Iwai etal., 2007). These chemicals act on the SA pathway in plants, inducing defense responses, but they do not directly affect the pathogens. Consequently, they are less likely to lead to drug resistance in the pathogens, a problem that often arises with fungicides and bactericides. Despite their abilities to activate the SA pathway, these chemicals do not negatively affect plant growth when applied at appropriate doses, because of their 'priming effect' (Conrath et al., 2002), which will be discussed below. Because of their favorable activities, these chemicals are produced commercially and broadly used in agriculture as chemical defense inducers (also known as 'plant activators'). Thus, the SA signaling pathway is the major target for disease control in agriculture.

\section{REGULATORY COMPONENTS IN THE SA DEFENSE SIGNALING PATHWAY}

Many regulatory components involved in the SA pathway have been identified in Arabidopsis. One of the most important ones is NON-EXPRESSOR OF PR1 (NPR1), a transcriptional cofactor that acts downstream of SA in the SA signaling pathway in Arabidopsis (Cao etal., 1997; Dong, 2004) and other plant species (Chern etal., 2005b; Malnoy etal., 2007; Endah et al., 2008; Le Henanff etal., 2009). A genome-wide gene expression analysis showed that more than 99\% of BTH-responsive gene expression was NPR1-dependent (Wang et al., 2006). In the absence of SA or pathogen challenge, NPR1 is retained in the cytoplasm as an oligomer via redox-sensitive intermolecular disulfide bonds (Mou et al., 2003). Upon activation of the SA pathway, the NPR1 monomer is released and enters the nucleus, where it activates defense gene transcription (Mou et al., 2003). This process is regulated by the sensing of cellular redox changes by NPR1 after its $S$-nitrosylation (Tada et al., 2008). Recently, it was reported that NPR1 also functions as an SA receptor (Wu etal., 2012). As a transcriptional cofactor, NPR1 interacts with members of the TGA family of TFs, thereby directly regulating the transcription of defense genes such as PR1 (Despres et al., 2003; Johnson et al., 2003; Durrant and Dong, 2004). Members of the WRKY TF family also act downstream of NPR1 (Wang et al., 2006). A negative regulator of NPR1, NIM1-INTERACTING1 (NIMIN1), antagonizes the NPR1-dependent SA pathway by binding to NPR1 (Weigel et al., 2001, 2005). Arabidopsis also has an SA-dependent but NPR1independent signaling pathway(s), which operates during the early phase of SA pathway activation (Li et al., 2004; Uquillas et al., 2004; Blanco et al., 2005).

The NPR1 protein is degraded by the ubiquitin-proteasome system (UPS) in the nucleus (Spoel et al., 2009). It has been proposed that UPS degradation of NPR1 has a dual role: first, constitutive degradation of NPR1 suppresses spurious activation 
of defense responses in the absence of pathogen attack; second, the SA-induced degradation of NPR1 underpins the full-scale activation of the transcriptional activity of NPR1. To gain a deeper understanding of the functions of NPR1 and its regulation, several studies have characterized NPR1 in rice and its orthologs in other plant species, and their signaling mechanisms.

\section{FITNESS COSTS OF DISEASE RESISTANCE AND THE PRIMING EFFECT}

Defense responses usually have fitness costs, which reflect the tradeoff between disease resistance and plant growth. The tradeoff is believed to be a consequence of resource allocation to defensive compounds and/or the toxicity of the defensive compounds themselves (Heil and Baldwin, 2002). Plants presumably have evolved inducible defense mechanisms to circumvent such negative effects of defense responses. Consistent with this idea, Arabidopsis mutants with constitutively activated defense responses, such as cpr (constitutive expressor of PR genes), in which the SA pathway is constitutively activated (Clarke et al., 2000), show severe growth defects (Figure 1A).

High doses of chemical defense inducers that act on the SA pathway reduce growth and seed set in plants, because of the fitness costs associated with strong defense induction (Heil et al., 2000). Application of these chemicals at appropriate doses does not directly induce defense responses, but pre-conditions plants for faster and stronger defense responses upon pathogen infection (Figure 1A), consequently imposing lower fitness costs on plants (Kauss et al., 1992; Katz et al., 1998; Thulke and Conrath, 1998; Conrath et al., 2002, 2006). This mode of action, known as 'priming,' is a characteristic feature of chemical defense inducers. Various mechanisms have been proposed to explain this priming effect, including metabolic changes, enhanced expression of MAP kinases and TFs, epigenetic changes such as histone modifications and DNA methylation, and modulation of defense-related hormone crosstalks (see below; Conrath, 2011; Pastor et al., 2013). The metabolic changes related to priming include the conversion of pathogen-induced SA into SA $2-\mathrm{O}-\beta$-D-glucose (SAG) by SA glucosyltransferase (Dean et al., 2005; Song, 2006). The pool of SAG in the vacuole serves as a source for rapid generation of SA by $\beta$-glucosidase upon pathogen challenge (Dean et al., 2005). Two MAP kinases, MPK3 and MPK6, are required for defense priming through the SA pathway in Arabidopsis (Beckers et al., 2009). Priming of Arabidopsis by BTH was shown to cause the accumulation of MAP kinase mRNA transcripts and inactive MAP kinase proteins. Then, amount of active MAP kinases increased only after infection by the incompatible Pseudomonas syringae pv. tomato (Pst) strain DC3000, invoking systemic immunity (Beckers et al., 2009).
A

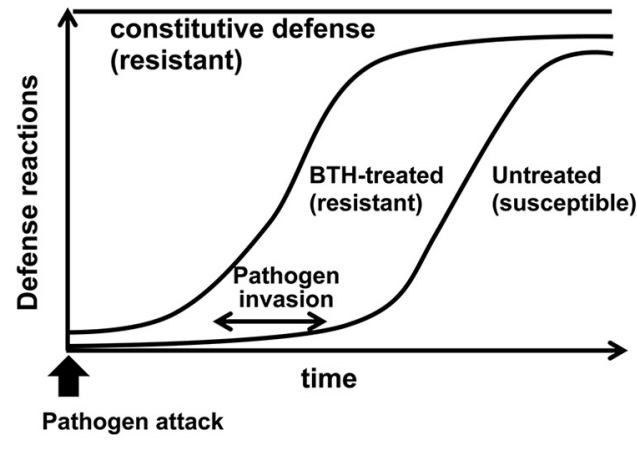

C

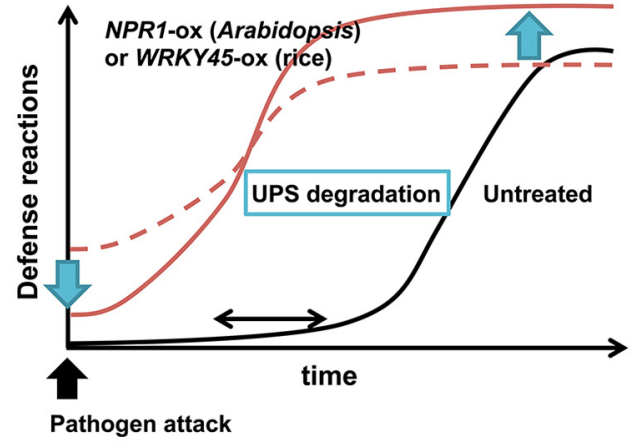

FIGURE 1 | Effects of priming on induced disease resistance. (A) In untreated wild-type plants, activation of defense reactions is slow and/or weak to counteract pathogens. By contrast, constitutive defense activation imposes fitness costs on plants. Chemical defense inducers such as BTH prime plants for rapid and/or strong defense reactions upon pathogen infection, thereby conferring plants with disease resistance without major
B

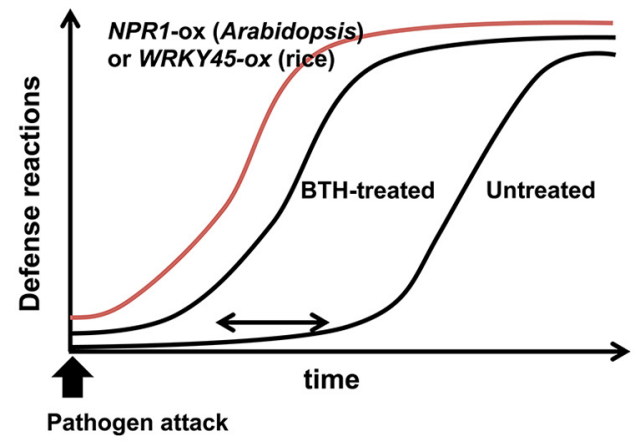

D

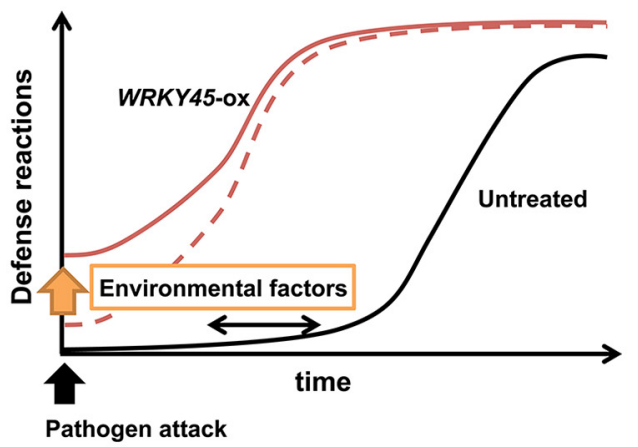

fitness costs. (B) Overexpression of NPR1 (Arabidopsis) or WRKY45 (rice) mimics priming by BTH. (C) UPS degradation of NPR1 (Arabidopsis) or WRKY45 (rice) suppresses basal defense levels in the absence of pathogens, and enhances defense levels upon pathogen infection, possibly contributing to the priming effect. (D) Environmental factors increase basal levels of WRKY45-dependent defense, leading to higher fitness costs. 
Epigenetic regulation also plays an important role in the priming effect (Saijo and Reimer-Michalski, 2013). March-Diaz et al. (2008) reported that Arabidopsis mutants with impaired incorporation of the histone variant H2A.Z showed up-regulated expression of SA-pathway genes and increased resistance to a virulent Pseudomonas syringae strain, indicating that H2A.Z has an important regulatory role in plant defense. Jaskiewicz et al. (2011) demonstrated that priming of SA-dependent defense was associated with NPR1-dependent post-translational modifications of histone $\mathrm{H} 3$ and $\mathrm{H} 4$ tails at the promoters of WRKY genes. Also, DNA methylation of defense genes induces defense priming. Pst DC3000 infection induced dynamic changes in DNA methylation of certain genes; for example, hypomethylation of SAresponsive genes leading to up-regulation of these genes (Dowen et al., 2012). Importantly, the changes in DNA methylation status of SA-inducible genes after Pst DC3000 infection were transmitted to the next generation together with SAR, a phenomenon known as trans-generational SAR (Luna et al., 2012).

In many cases, overexpression of defense signaling components negatively affects plant growth as the price of disease resistance (Delteil et al., 2010). However, overexpression of NPR1 in Arabidopsis conferred resistance to Pseudomonas syringae and Peronospora parasitica with no obvious detrimental effects on plant growth (Cao et al., 1998). NPR1-overexpressing Arabidopsis plants were indistinguishable from wild-type Arabidopsis plants when grown in field conditions or in a growth chamber, whereas $c p r$ mutants showed severe growth defects as a result of constitutive defense expression (Heidel et al., 2004). These observations indicate that like chemical defense inducers, overexpression of NPR1 primes defense responses, rather than directly activating them (Figure 1B). The post-translational regulation of NPR1, including its redox-responsive nucleus localization described above, likely contributes to the priming effect (Mou et al., 2003; Tada et al., 2008). In particular, the dual mode of the ubiquitin-proteasome degradation of NPR1 (Spoel et al., 2009) probably plays an important role in NPR1-dependent priming. The UPS degradation of NPR1 decreases basal NPR1 levels in the absence of pathogens (Figure 1C), and it also enhances defense levels upon pathogen attack or activation of the SA pathway (Figure 1C). For example, Cao et al. (1998) reported that the level of NPR1 protein was only threefold higher in NPR1-ox Arabidopsis plants than in wild-type Arabidopsis in the absence of pathogen infection, whereas the difference in NPR1 transcript levels was 28 -fold. The small increase in basal levels of NPR1 proteins by NPR1 overexpression culminated in the low induction level of the PR1 gene in these plants (Cao et al., 1998).

As well as the tradeoff between pathogen defense and plant growth, there are tradeoffs between responses to biotic and abiotic stresses in plants. These tradeoffs likely result from the reallocation of resources from growth to defense against the most life-threatening stress in each situation (Matyssek et al., 2005; Fujita et al., 2006). Additionally, there are tradeoffs between responses to different types of biotic stresses; e.g., pathogenic microbes vs. herbivore insects and biotrophic pathogens vs. necrotrophic pathogens. Besides the SA pathway, there are several other signaling pathways that mediate responses to intrinsic developmental and environmental cues. These pathways involve abscisic acid (ABA), auxins, brassinosteroids, cytokinins, ethylene, gibberellin, jasmonate (JA), reactive oxygen species (ROS), and calcium ions. There is an increasing body of evidence that these signaling pathways interconnect in a complex network (RobertSeilaniantz et al., 2011; Cui and Luan, 2012; Pieterse et al., 2012; De Vleesschauwer et al., 2013). There can be synergistic or antagonistic crosstalks among different signaling pathways in response to multiple environmental cues. The pathways and the crosstalks among them balance environmental responses with the regulation of plant growth and development (Fujita et al., 2006). Because of the crosstalks among signaling pathways, modification of the SA-signaling pathway to improve disease resistance can adversely affect plant growth and/or abiotic-stress responses. Similarly, abiotic stresses can interfere with SA-pathway-dependent disease resistance. These are among the important points to consider when using signaling components to develop disease resistant crops.

\section{THE SA SIGNALING PATHWAY IN RICE}

In tobacco and Arabidopsis, the basal levels of SA are low $(<100 \mathrm{ng} / \mathrm{g}$ fresh weight) but they markedly increase upon pathogen infection (Malamy and Klessig, 1992). By contrast, the basal SA levels in rice leaves are very high (8-37 $\mu \mathrm{g} / \mathrm{g}$ fresh weight), and they do not change significantly, either locally or systemically, upon pathogen attack (Silverman etal., 1995). Because of these observations, the importance of the SA pathway in pathogen defense was controversial during early phases of research on defense signaling in rice. It has been reported that in rice, $\mathrm{SA}$ at high levels functions as an antioxidant that protects tissues from oxidative damage caused by aging, pathogen attack, or abiotic stresses (Yang et al., 2004). However, there is increasing evidence that the SA signaling pathway is also important in mediating defense signaling in rice.

Despite the high endogenous levels of SA in rice, exogenous application of SA or BTH activates its defenses against pathogens (Shimono et al., 2007). The SA levels further increase in response to probenazole, a chemical defense inducer acting upstream of SA, in adult rice plants, but not juvenile ones (Iwai et al., 2007). Like the SA signaling pathway in Arabidopsis and other dicots, the SA signaling pathway in rice also involves an NPR1 protein (OsNPR1/NH1) that acts downstream of SA (Chern et al., 2001; Fitzgerald et al., 2004; Yuan et al., 2007; Sugano et al., 2010). Resistance to M. oryzae induced by BTH was compromised in OsNPR1/NH1-knockdown (-kd) rice (Sugano et al., 2010). Similarly, Xoo resistance induced by BTH (Sugano et al., 2010) or without it (Yuan et al., 2007) was compromised in OsNPR1/NH1-kd rice. Like NPR1 in Arabidopsis, OsNPR1/NH1 proteins are usually localized in the cytosol, but move into the nucleus in response to redox changes. Mutations at two conserved cysteines abolished this translocalization (Yuan et al., 2007). OsNPR1/NH1 interacts with b-ZIP-type TGA TFs to regulate SA-responsive genes (Fitzgerald et al., 2005). OsNPR1/NH1 function was repressed by direct interaction with negative regulator of disease resistance (NRR; Chern et al., 2005a), a homolog of Arabidopsis NIMIN (Weigel et al., 2001, 2005). These results suggest that post-translational regulation and action mode of NPR1 
proteins is conserved between Arabidopsis and rice, with an exception of their proteasome degradation (see below). Overexpression of OsNPR1/NH1 was shown to confer strong resistance to both Xoo and M. oryzae (Chern et al., 2005b; Sugano et al., 2010).

WRKY45 was identified in the japonica rice cultivar Nipponbare as a TF that is essential for BTH-induced resistance to $M$. oryzae. Expression of WRKY45 is inducible by SA and $\mathrm{BTH}$. The effect of BTH to induce $M$. oryzae resistance was severely compromised in WRKY45-kd rice transformants (Shimono et al., 2007). Resistance to $M$. oryzae induced by other chemical defense inducers, probenazole and tiadinil, was shown to be dependent on WRKY45, as was BTH-induced Xoo resistance (Shimono et al., 2012). The effects of WRKY45-knockdown on disease resistance were barely observed in the absence of chemical treatments (Shimono et al., 2012). WRKY45 is usually up-regulated after pathogen infection, even without chemical treatments, but the timing of the induction is not early enough to counteract pathogens. Thus, the induction of WRKY45 transcription before pathogen infection underpins chemical-induced resistance. WRKY45-overexpressing (WRKY45-ox) rice, as well as plants treated with BTH at appropriate doses, showed increased levels of WRKY45 transcripts but did not exhibit major defense responses in the absence of pathogen infection under particular conditions (Shimono et al., 2007). WRKY45-ox rice plants, in which WRKY45 was driven by the strong constitutive maize ubiquitin promoter, were strongly resistant to both $M$. oryzae (Shimono etal., 2007) and Xoo (Shimono etal., 2012). However, these plants were susceptible to Rhizoctonia solani, the causal agent of sheath blight disease (Shimono et al., 2007). Microscopy studies have shown that $M$. oryzae resistance resulting from WRKY45 overexpression mainly results from pre-invasive defense responses, which restrict fungal entry into rice cells. However, there are also post-invasive defense responses that target the fungal cells penetrating through the pre-invasive defense layer (Shimono et al., 2012).

Surprisingly, the alleles of WRKY45 in japonica and indica rice subspecies play different roles in the defense responses to Xoo (Tao et al., 2009). Overexpression of indica-derived WRKY45 (WRKY45-2) conferred Xoo resistance, but overexpression of japonica-derived WRKY45 (WRKY45-1) rendered rice more susceptible to Xoo. Both of the alleles conferred resistance to $M$. oryzae. Thus, WRKY45-1 has opposite effects against the two (hemi)biotrophic pathogens, $M$. oryzae and Xoo. The results for WRKY45-1 reported by (Tao et al., 2009) contradict those obtained by Shimono et al. (2012), who reported that rice overexpressing japonica-derived WRKY45 (WRKY45-1) showed strong resistance to Xoo. These two studies used different constructs for WRKY45 overexpression, but both constructs were driven by the same maize ubiquitin promoter. Shimono et al. (2012) used the cDNA for WRKY45, while Tao et al. (2009) used the genomic fragment of WRKY45, which included the sequences upstream of the transcriptional start site and introns. It is possible that the contradicting results are because of the different constructs used in the two studies, although there are other possible explanations; for example, differences in the genetic backgrounds of the rice varieties used as hosts for these transgenic studies. Examination of WRKY45 proteins in the transformants using an
anti-WRKY45 antibody (Shimono et al., 2012) should address this issue.

NPR1 regulates nearly all of the BTH-responsive genes in Arabidopsis (Wang et al., 2006), except during early phases of pathogen infection (Li et al., 2004; Uquillas et al., 2004; Blanco et al., 2005). By contrast, the SA pathway in rice appears to branch into OsNPR1/NH1 - and WRKY45-mediated sub-pathways (Figure 2), as revealed by an epistasis analysis and global gene expression analyses of BTH-responsive genes in OsNPR1/NH1-kd and WRKY45kd rice transformants (Shimono et al., 2007; Sugano et al., 2010; Takatsuji et al., 2010; Nakayama et al., 2013). Overexpression of OsNPR1/NH1 down-regulated some genes, but up-regulated many other genes including numerous defense-related genes. The genes down-regulated by OsNPR1/NH1 included several involved in photosynthesis and protein synthesis. These results suggest that one of the functions of OsNPR1/NH1 is to divert resources from housekeeping cellular activities such as photosynthesis to defense responses (Figure 2; Sugano et al., 2010). A similar function was also inferred for Arabidopsis NPR1, based on the genome-wide transcriptome analysis of BTH-responsive genes in the Arabidopsis npr1 mutant (Wang et al., 2006; Sugano et al., 2010).

A recent study reported that most of the WRKY45-dependent genes $(85 \%, 220$ genes) in rice were up-regulated in response to BTH (Nakayama et al., 2013). In addition to putative defense genes such as those encoding PR proteins and other proteins involved in secondary metabolism of defense products, several genes for defense-related TFs were directly or indirectly regulated downstream of WRKY45 (Figure 2; Nakayama etal., 2013). These TFs included WRKY62, which negatively regulates Xoo resistance dependent on the PRR Xa21 (Peng et al., 2008); OsNAC4, a positive regulator of programmed cell death associated with the hypersensitive reaction (Kaneda et al., 2009); and OsHSF1, a negative regulator of plant cell death through decreasing reactive oxygen species (ROS) levels (Yamanouchi et al., 2002). These results suggest that a transcriptional cascade underpins WRKY45-dependent defense reactions in rice (Figure 2; Nakayama et al., 2013).

WRKY13 has also been implicated in the SA pathway in rice. This TF positively regulates SA-pathway-dependent disease resistance against M. oryzae and Xoo (Figure 2; Qiu etal., 2007). WRKY13 has been shown to play a role in regulating antagonistic crosstalk between SA- and JA-dependent signaling pathways, acting upstream of OsNPR1/NH1 (Qiu et al., 2007, 2008, 2009). Recently, WRKY13 was reported to function as a transcriptional repressor. WRKY13 repressed drought tolerance through downregulating expression of the gene encoding the downstream TF SNAC1 (Figure 2; Xiao et al., 2013). SNAC1 is a positive regulator of drought tolerance (Hu et al., 2006) and its suppression by WRKY13 resulted in increased sensitivity to drought (Xiao et al., 2013). WRKY13 also transcriptionally represses WRKY45-1, which negatively regulates Xoo resistance (Tao et al., 2009); consequently, WRKY13 increases Xoo resistance. Here, the repression of WRKY45-1 by WRKY13 is puzzling, because previous studies demonstrated that both WRKY45-1 (Shimono et al., 2007; Tao et al., 2009) and WRKY13 (Qiu et al., 2007) are positive regulators of $M$. oryzae resistance.

WRKY76 is another WRKY transcriptional repressor that is inducible by SA/BTH (Shimono et al., 2007), as well as wounding, 


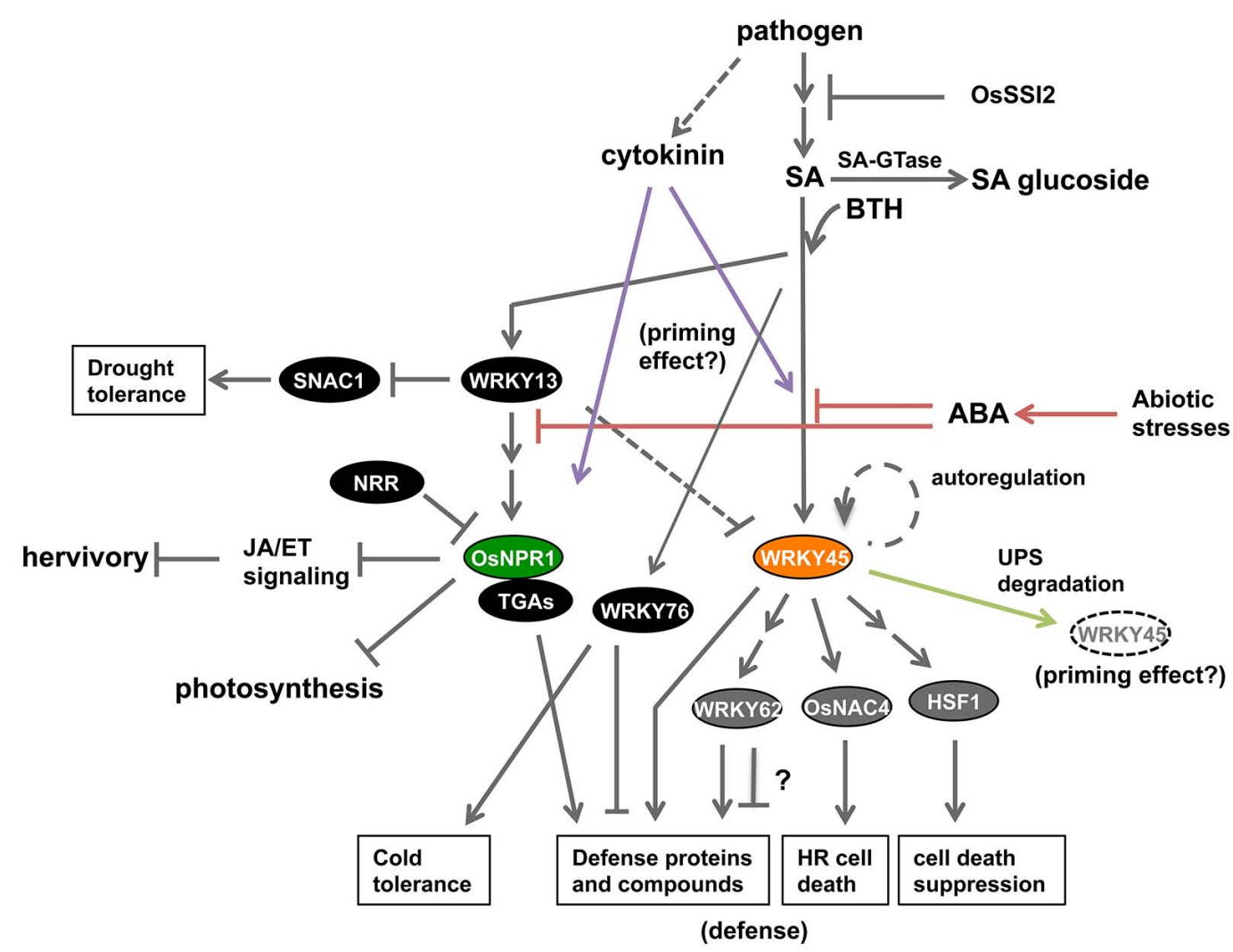

FIGURE 2 | Current status of knowledge about the SA signaling pathway in rice. The rice SA pathway branches into OsNPR1- and WRKY45-dependent sub-pathways. OsNPR1 positively regulates defense reactions and suppresses JA signaling, and also down-regulates cellular activities such as photosynthesis, thereby playing a role in resource allocation during defense responses. WRKY45 positively regulates disease resistance through downstream transcription factors; WRKY62, OsNAC4, and HSF1. The role of WRKY62 in defense needs further investigation because there are conflicting data. The degradation of WRKY45 by the UPS has two effects: defense suppression in the absence of pathogens; and defense enhancement upon
SA-pathway activation and/or pathogen infection. ABA signaling, which mediates abiotic stresses, negatively regulates the SA-pathway-dependent defense by acting upstream of WRKY45 and OsNPR1 (red lines). Cytokinin signaling, which is activated by $M$. oryzae infection, acts synergistically with the SA pathway to trigger defense responses, thereby possibly underpinning the priming effect (purple lines). WRKY13, a transcriptional repressor, positively regulates OsNPR1 and disease resistance by acting upstream of OsNPR1. WRKY13 also plays a role in down-regulating drought tolerance of rice through repressing SNAC1. By contrast, WRKY76 suppresses disease resistance while enhancing cold tolerance. low temperature, and ABA (Yokotani et al., 2013). Overexpression of WRKY76 increased susceptibility of rice to M. oryzae and Xoo (Figure 2; Seo et al., 2011; Yokotani et al., 2013) but improved cold tolerance (Yokotani et al., 2013). These results suggest that WRKY76 plays a role in the crosstalk between disease resistance and abiotic stress tolerance.

WRKY30 is a newly identified interesting TF in that it is involved in both SA and JA pathways. Its transcripts are rapidly inducible by both SA and JA (Peng et al., 2012). In addition, its overexpression induces the expression of WRKY45 (Han et al., 2013), the SA-pathway specific gene, as well as LOX and AOS2 genes (Peng et al., 2012), the JA-pathway marker genes. Strikingly, WRKY30-ox rice transformants are resistant to both (hemi)biotrophic pathogens (M. oryzae and Xoo) and R. solani, a necrotrophic pathogen (Peng et al., 2012; Han et al., 2013), consistent with the fact that WRKY30 is involved in both SA and JA pathways.

There are several other examples of proteins that negatively or positively affect disease resistance in rice. For example, OsSGT1
(Oryza sativa UDP-glucose:SA glucosyltransferase 1), which catalyzes the conversion of free SA into SA-O-B-glucoside, can promote probenazole-inducible resistance (Figure 2; Umemura et al., 2009). OsSSI2, the ortholog of Arabidopsis SSI2 (Suppressor of SA insensitivity 2; Shah et al., 2001), encodes a fatty-acid desaturase, and was shown to act upstream of WRKY45 to negatively regulate WRKY45-dependent resistance to M. oryzae and Xoo (Figure 2; Jiang et al., 2009).

\section{PROTEASOME DEGRADATION OF WRKY45}

In rice, WRKY45 is degraded by the UPS in the nucleus (Figure 2; Matsushita etal., 2013). The regulation of WRKY45 by the UPS has a dual role, similar to the case of Arabidopsis NPR1 (Matsushita et al., 2013). WRKY45 is constantly degraded by the UPS in the absence of pathogens and/or defense signals. However, in the presence of an SA signal and/or pathogen infection, there is increased WRKY45-dependent induction of defense responses. It was proposed that the induced accumulation of WRKY45 in response to the SA signal exceeds the rate of its degradation 
by the UPS. Therefore, the surplus WRKY45 can bind to target promoters, and the transcriptional activity of WRKY45 is enhanced by UPS-mediated turnover. Based on studies in human and yeast, multiple models have been proposed to explain the role of UPS degradation of TFs in enhancing their transcriptional activities (Lipford and Deshaies, 2003; Muratani and Tansey, 2003). The dual mode of UPS regulation of WRKY45 is probably partly responsible for the priming effect of WRKY45-dependent defense (Spoel et al., 2009; Matsushita et al., 2013). WRKY45ox rice plants, despite their extremely strong resistance to $M$. oryzae and Xoo, show only minor fitness costs, at least under particular growth conditions. It is likely that UPS degradation contributes to reducing the fitness costs of WRKY45 overexpression by decreasing the basal level of WRKY45 protein, and/or by suppressing the spurious induction of WRKY45 proteins in the absence of pathogens (Figure 1C). Also, the UPS degradation of WRKY45 on target promoters increases its transcriptional activity, thereby enhancing the expression levels of defense genes (Figure 1C).

Unlike Arabidopsis NPR1, OsNPR1/NH1 was not degraded by the UPS (Matsushita etal., 2013). Overexpression of $O s N P R 1 / \mathrm{NH} 1$ in rice induced constitutive activation of $P R$ gene expression, accompanied by lesion-mimic symptoms and light hypersensitivity (Chern et al., 2005b). NPR1 overexpression in Arabidopsis did not trigger defense reactions until subsequent induction by chemicals or pathogen infection (Cao etal., 1998). The presence or absence of UPS degradation, which affects the levels of transgene products, could be responsible for the differences in the phenotypes of transformants; that is, priming vs. direct defense responses.

Recently, we have shown that the UPS degradation of WRKY45 plays an important role in blast resistance associated with $\mathrm{Pb} 1$ (Panicle blast 1), an R-protein-like coiled-coil-nucleotide-binding site leucine-rich repeat (CC-NB-LRR) protein (Inoue et al., 2013). $R$-gene-mediated disease resistance is usually race-specific and is prone to breakdown. By contrast, the resistance conferred by $P b 1$ is non-race-specific and durable against $M$. oryzae in rice, despite the $R$-like structure of $P b 1$. The $P b 1$-induced resistance is especially strong in rice at the adult phase; therefore, it has been used for breeding (Fujii and Hayano-Saito, 2007; Hayashi et al., 2010). The blast resistance associated with $P b 1$ is clearly dependent on WRKY45, because WRKY45-knockdown significantly decreased $\mathrm{Pb1}$-dependent blast resistance in $\mathrm{Pb1}$ containing rice lines and $\mathrm{Pbl}$-overexpressing rice transformants (Inoue et al., 2013). Pb1 and WRKY45 were shown to interact in the nucleus, and this interaction inhibited the UPS degradation of WRKY45 (Inoue et al., 2013). Based on these results, we propose that the protection of WRKY45 from UPS degradation at least partly explains $\mathrm{Pb} 1$-dependent blast resistance (Inoue et al., 2013).

\section{SIGNALING CROSSTALKS MODIFY SA-PATHWAY- DEPENDENT DEFENSE RESPONSES}

As in dicots, positive and negative crosstalks between the SA signaling pathway and other signaling pathways are also prevalent in rice, for which detailed reviews can be found elsewhere (De
Vleesschauwer et al., 2013; Takatsuji and Jiang, 2014). Here, I discuss the significance of these signaling crosstalks in plants' defense systems and their potential uses in genetic engineering strategies to improve disease resistance by modifying defense signaling components.

Application of exogenous ABA compromised rice resistance to M. oryzae (Matsumoto, 1980; Koga et al., 2004; Bailey et al., 2009; Jiang et al., 2010), Xoo (Xu et al., 2013) and the migratory nematode Hirschmanniella oryzae (Nahar et al., 2012). By contrast, inhibition of $\mathrm{ABA}$ biosynthesis, degradation of $\mathrm{ABA}$, or blocking of ABA signaling enhanced rice resistance to M. oryzae (Koga et al., 2004; Yazawa et al., 2012) and Xoo (Xu et al., 2013). These results are consistent with the observations that abiotic stresses such as low temperature and drought, which induce ABA accumulation, render rice plants more susceptible to blast disease (Kahn and Libby, 1958; Bonman et al., 1988; Gill and Bonman, 1988; Koga et al., 2004). Jiang et al. (2010) detected ABA in the fungal bodies and culture media of M. oryzae. Thus, it is possible that the fungus produces its own ABA to attenuate the plant defense system. Recent studies have provided evidence that antagonistic crosstalk between ABA signaling and SA signaling underpins these phenomena in rice (Jiang et al., 2010; Sugano et al., 2010; Yazawa et al., 2012; Xu et al., 2013) as well as in Arabidopsis (Yasuda et al., 2008). ABA suppressed SA/BTH- or pathogen-induced up-regulation of WRKY45 and OsNPR1/NH1 (Figure 2; Jiang et al., 2010). Overexpression of OsNPR1/NH1 or WRKY45 largely eliminated increased-blast susceptibility induced by $A B A$, suggesting that $A B A$ acts upstream of WRKY45 and OsNPR1/NH1 in the rice SA pathway (Jiang et al., 2010; Xu et al., 2013). This antagonistic crosstalk presumably redirects resources from pathogen defense to the abiotic stress response, thereby enabling plants to survive under abiotic stress conditions in nature. Recently, we showed that the MAP kinase OsMPK6 phosphorylates WRKY45 in an SA-dependent manner (Ueno et al., 2013). Our data suggest that OsMPK6 is the node of convergence of this antagonistic crosstalk.

Cytokinin-mediated signaling also plays an important role in pathogen defenses by interacting with the SA pathway. In Arabidopsis, cytokinins were shown to act on the SA-signaling pathway synergistically, enhancing resistance to the hemibiotrophic bacterial pathogen Pst DC3000 and the biotrophic oomycete pathogen Hyaloperonospora Arabidopsis (Choi et al., 2010; Argueso et al., 2012). In this process, Arabidopsis response regulator 2 (ARR2), a TF activated by cytokinin signaling, forms a complex with TGA3 (TGA1a-related 3), an SA-responsive TF. This complex activates the transcription of $P R$ genes, resulting in disease resistance (Choi et al., 2010, 2012). The synergistic relationship between cytokinin signaling and SA signaling has also been observed in rice (Figure 2). Co-treatment of rice leaf blades with cytokinins and SA strongly induced the expression of the defense genes $P R 1 b$ and PBZ1 (probenazole-inducible protein 1), whereas treatment with either one alone only slightly increased their expression levels (Jiang et al., 2013). The induction of these defense genes was diminished by RNAi-knockdown of OsNPR1/NH1 or WRKY45, indicating that the synergistic crosstalk depends on these central regulators of the SA pathway. The levels of cytokinin species were shown to increase in rice leaf blades during blast infection (Jiang et al., 2013). Given that M. oryzae can produce and 
secrete cytokinins (Jiang et al., 2013), fungus-derived cytokinins could contribute, at least partly, to the increased cytokinin level in infected leaves. These cytokinin species, whether derived from the fungus or produced de novo in the plant, could benefit the pathogen by promoting nutrient translocation to the infection sites (Walters et al., 2008). Conversely, the synergistic crosstalk between cytokinin signaling and SA signaling could trigger defense responses in plants primed for defense through the SA signaling pathway. Thus, both pathogens and hosts exploit cytokinin signaling. Recently, we have demonstrated that diterpenoid phytoalexin synthetic genes were primed by BTH and proposed that the SAcytokinin synergism plays a crucial role in full activation of these genes (Akagi et al., 2014). Thus, this signaling crosstalk represents a new possible mechanism that could underlie priming-based pathogen defense in rice.

Both negative and positive crosstalks between SA and JA signaling have been reported in many plant species, although antagonistic crosstalk is more common (Thaler et al., 2012). Several studies have demonstrated SA-JA crosstalk in rice. Like NPR1 in Arabidopsis (Spoel et al., 2003), OsNPR1/NH1 has been implicated in SA-JA antagonistic crosstalk in rice. Overexpression of OsNPR1/NH1 strongly activated SA-responsive genes and suppressed JA marker genes (Yuan etal., 2007). Consequently, OsNPR1/NH1 overexpression rendered rice more susceptible to herbivorous insects (Yuan et al., 2007; Li etal., 2013), but conferred strong resistance to M. oryzae and Xoo. A role of WRKY13 in SA-JA antagonistic crosstalk has also been suggested (Qiu et al., 2007, 2008, 2009). Several studies have suggested that the two hormone signaling pathways may feed into a common defense system that is effective against both biotrophic and necrotrophic pathogens in rice (Garg et al., 2012; Liu et al., 2012; Tong et al., 2012; Yamada et al., 2012; De Vleesschauwer et al., 2013; Takatsuji and Jiang, 2014).

\section{DEVELOPMENT OF DISEASE-RESISTANT RICE USING COMPONENTS OF THE SA SIGNALING PATHWAY}

The components of the SA signaling pathway are important genetic resources for improving rice resistance against pathogens using transgenic approaches. The NPR1 proteins (in Arabidopsis and rice) and WRKY45 positively regulate the rice SA pathway and their up-regulation enhances rice resistance against $M$. oryzae and Xoo, and possibly other (hemi)biotrophic pathogens. Overexpression of WRKY13 also enhances M. oryzae and Xoo resistance through modulating the SA pathway (Qiu et al., 2007). Although these factors have strong potential to prevent diseases, their constitutive overexpression at high levels has been accompanied by various negative effects, which were often environmentdependent. Overexpression of Arabidopsis NPR1 in rice results in lesion mimic/cell death phenotype under specific environmental condition (Fitzgerald et al., 2004). OsNPR1/NH1-ox rice plants showed spontaneous lesion-mimic symptoms without other developmental effect when grown in a greenhouse; however, a dwarf phenotype accompanied by increased SA contents occurred after cultivation in a growth chamber under low light intensity (Chern et al., 2005b). These observations are presumably due to light-sensitive tradeoff between plant growth (dwarf) and disease resistance (increased SA). Overexpression of WRKY45 also resulted in growth retardation that was dependent on the cultivation conditions (Shimono et al., 2007). The WRKY45-ox rice plants cultivated in a growth chamber showed severely restricted growth accompanied by up-regulation of $P R$ genes, whereas those cultivated in a greenhouse showed only minor growth retardation (Shimono et al., 2007). Multiple environmental factors negatively affected the growth of WRKY45-ox rice plants, and the negative effects were correlated with elevated WRKY45-dependent defense responses in the absence of pathogens (Figure 1D; Goto et al., in press). Overexpression of WRKY13 resulted in reduced drought tolerance (Figure 2; Xiao et al., 2013). These phenomena are because of tradeoffs between disease resistance and plant growth and/or abiotic stress tolerance. Meanwhile, OsNPR1/NH1ox rice plants are less tolerant to herbivore, which can be regarded as a tradeoff between the responses to different biotic stresses, pathogens and pests (Yuan et al., 2007; Li et al., 2013). These problems must be overcome to develop practicable disease-resistant rice lines.

Suppression of negative regulators of the SA pathway can also increase disease resistance of rice. In the case of OsSSI2, the complete loss-of-function mutation of its gene negatively affected plant growth, because of the constitutive activation of the SA pathway (Jiang et al., 2009). This may reflect the tradeoff between defense and growth, or result from the toxicity of the defense products. Meanwhile, the incomplete loss-of-function of this gene by RNAi resulted in strong resistance to both M. oryzae and Xoo without major negative effects on plant growth (Jiang et al., 2009). These results suggest that controlling the activation of defense signaling at moderate levels is one way to manage the tradeoff effects.

The priming effect is another crucial factor in alleviating the tradeoff between disease resistance and growth/abiotic stress resistance. In previous studies on rice overexpressing WRKY45 or Arabidopsis overexpressing NPR1, it was particularly important to control their expression levels to fully realize the benefit of the priming effect. This is because like chemical inducers, overexpression of WRKY45 or NPR1 leads to dose-dependent defense responses, ranging from direct defense to priming (Conrath et al., 2002). Constitutive expression of Arabidopsis NPR1 had a priming effect on Arabidopsis transformants (Heidel et al., 2004), whereas that of OsNPR1/NH1 in rice led to constitutive defense activation (Chern et al., 2005b). One of the differences between these counterpart proteins is the presence (Arabidopsis) or absence (rice) of their UPS degradation (Spoel et al., 2009; Matsushita et al., 2013). UPS degradation reduces the basal levels of the target protein, and consequently, decreases the fitness costs associated with its defense-activating function.

Unlike OsNPR1/NH1, rice WRKY45 is degraded by the UPS. The dual role of UPS degradation at least partly explains the priming effect caused by WRKY45 overexpression (Matsushita et al., 2013). There is a synergistic interaction between SA and cytokinin signaling (Jiang et al., 2013), and this interaction also likely contributes to the priming effect on the basis of the transcriptional regulation of diterpenoid phytoalexin biosynthetic genes (Akagi et al., 2014). However, the high-level expression of WRKY45 still imposed significant fitness costs, which were exacerbated by some environmental factors (Shimono et al., 2007). Recently, we found that controlling the level of WRKY45 expression at moderate levels 
using a weaker constitutive promoter largely eliminated the fitness costs and environmental sensitivity related to WRKY45 expression, while retaining strong disease resistance (Goto et al., in press). The use of pathogen-responsive or tissue-specific promoters is another strategy to drive gene expression when and where pathogens invade. We have screened and identified a pathogen-responsive promoter from rice that can confer strong resistance to both $M$. oryzae and Xoo by driving WRKY45 expression without causing a yield penalty in field-grown rice crops. Details of these studies will be described elsewhere.

\section{FUTURE PROSPECTS}

Disease resistance strategies using the components of the SAsignaling pathway have the potential to be effective and versatile. However, their success depends on managing the tradeoffs between pathogen defense and plant growth and/or abioticstress tolerance. In this article, I discussed the importance of the priming effect and transgene expression levels. The use of pathogen-inducible promoters is one effective strategy for conditional transgene expression. However, these strategies do not exploit the full potential of the signaling components, because their potential is sacrificed to some extent to manage the tradeoff. In principle, the tradeoffs reflect the plant's strategy to prioritize the responses to the most significant life-threating stress at the cost of plant growth or the responses to less serious stresses under resource-limited conditions. However, such regulation is probably not essential in crops cultivated under resource-rich conditions. Rather, unnecessary tradeoffs can decrease crop yields by limiting the resources available for plant growth and development. There is mounting evidence that signaling crosstalks play roles in tradeoffs. By disconnecting such crosstalks via targeting precise molecular mechanisms, it will become possible to establish even more robust disease resistance without adversely affecting the crop yield or abiotic stress tolerance. Although several signaling components have been reported to affect the interconnections among pathways, many of them act indirectly, and their manipulation is unlikely to disconnect the crosstalks. Therefore, it is important to identify and manipulate the molecules that play direct roles in regulating crosstalks. These are probably among the most important challenges for improving the disease resistance of crops in the future.

\section{ACKNOWLEDGMENTS}

This work was supported by grants from the Japanese Ministry of Agriculture, Forestry and Fisheries (Genomics-based Technology for Agricultural Improvement, GMA0001, GMO1006 and PGE1005) and JSPS KAKENHI Grant Number 25292032.

\section{REFERENCES}

Akagi, A., Fukushima, S., Okada, K., Jiang, C.-J., Yoshida, R., Nakayama, A., et al. (2014). WRKY45-dependent priming of diterpenoid phytoalexin biosynthesis in rice and the role of cytokinin in triggering the reaction. Plant Mol. Biol. 86, 171-183. doi: 10.1007/s11103-014-0221-x

Argueso, C. T., Ferreira, F. J., Epple, P., To, J. P., Hutchison, C. E., Schaller, G. E., etal. (2012). Two-component elements mediate interactions between cytokinin and salicylic acid in plant immunity. PLoS Genet. 8:e1002448. doi: 10.1371/journal.pgen. 1002448

Ausubel, F. M. (2005). Are innate immune signaling pathways in plants and animals conserved? Nat. Immunol. 6, 973-979. doi: 10.1038/ni1253
Bailey, T., Zhou, X., Chen, J., and Yang, Y. (2009). "Role of ethylene, abscisic acid and MAP kinase pathways in rice blast resistance," in Advances in Genetics, Genomics and Control of Rice Blast Disease, ed. G.-L. A. V. Wang, (Netherlands: Springer), 185-190. doi: 10.1007/978-1-4020-9500-9_19

Beckers, G. J. M., Jaskiewicz, M., Liu, Y. D., Underwood, W. R., He, S. Y., Zhang, S. Q., et al. (2009). Mitogen-activated protein kinases 3 and 6 are required for full priming of stress responses in Arabidopsis thaliana. Plant Cell 21, 944-953. doi: 10.1105/tpc.108.062158

Blanco, F., Garreton, V., Frey, N., Dominguez, C., Perez-Acle, T., Van Der Straeten, D., et al. (2005). Identification of NPR1-dependent and independent genes early induced by salicylic acid treatment in Arabidopsis. Plant Mol. Biol. 59, 927-944. doi: $10.1007 /$ s11103-005-2227-x

Boller, T., and He, S. Y. (2009). Innate immunity in plants: an arms race between pattern recognition receptors in plants and effectors in microbial pathogens. Science 324, 742-744. doi: 10.1126/science.1171647

Bonman, J. M., Khush, G. S., and Nelson, R. J. (1992). Breeding rice for resistance to pests. Annu. Rev. Phytopathol. 30, 507-528. doi: 10.1146/annurev.py.30.090192.002451

Bonman, J. M., Sanchez, L. M., and Mackill, A. O. (1988). Effects of water deficit on rice blast. II. Disease-development in the field. J. Plant Prot. Trop. 5, 67-73.

Cao, H., Glazebrook, J., Clarke, J. D., Volko, S., and Dong, X. (1997). The Arabidopsis NPR1 gene that controls systemic acquired resistance encodes a novel protein containing ankyrin repeats. Cell 88, 57-63. doi: 10.1016/S0092-8674(00)81858-9

Cao, H., Li, X., and Dong, X. (1998). Generation of broad-spectrum disease resistance by overexpression of an essential regulatory gene in systemic acquired resistance. Proc. Natl. Acad. Sci. U.S.A. 95, 6531-6536. doi: 10.1073/pnas.95.11.6531

Chern, M., Canlas, P. E., Fitzgerald, H. A., and Ronald, P. C. (2005a). Rice NRR, a negative regulator of disease resistance, interacts with Arabidopsis NPR1 and rice NH1. Plant J. 43, 623-635. doi: 10.1111/j.1365-313X.2005.02485.x

Chern, M., Fitzgerald, H. A., Canlas, P. E., Navarre, D. A., and Ronald, P. C. (2005b). Overexpression of a rice NPR1 homolog leads to constitutive activation of defense response and hypersensitivity to light. Mol. Plant Microbe Interact. 18, 511-520. doi: 10.1094/MPMI-18-0511

Chern, M. S., Fitzgerald, H. A., Yadav, R. C., Canlas, P. E., Dong, X., and Ronald, P. C. (2001). Evidence for a disease-resistance pathway in rice similar to the NPR1-mediated signaling pathway in Arabidopsis. Plant J. 27, 101-113. doi: 10.1046/j.1365-313x.2001.01070.x

Choi, J., Huh, S. U., Kojima, M., Sakakibara, H., Paek, K. H., and Hwang, I. (2010). The cytokinin-activated transcription factor ARR2 promotes plant immunity via TGA3/NPR1-dependent salicylic acid signaling in Arabidopsis. Dev. Cell 19, 284-295. doi: 10.1016/j.devcel.2010.07.011

Choi, J., Lee, J., Kim, K., Cho, M., Ryu, H., An, G., et al. (2012). Functional identification of OsHk6 as a homotypic cytokinin receptor in rice with preferential affinity for iP. Plant Cell Physiol. 53, 1334-1343. doi: 10.1093/pcp/pcs0799

Clarke, J. D., Volko, S. M., Ledford, H., Ausubel, F. M., and Dong, X. (2000). Roles of salicylic acid, jasmonic acid, and ethylene in cpr-induced resistance in Arabidopsis. Plant Cell 12, 2175-2190. doi: 10.1105/tpc.12.11.2175

Conrath, U. (2011). Molecular aspects of defence priming. Trends Plant Sci. 16, 524-531. doi: 10.1016/j.tplants.2011.06.004

Conrath, U., Beckers, G. J. M., Flors, V., Garcia-Agustin, P., Jakab, G., Mauch, F., et al. (2006). Priming: getting ready for battle. Mol. Plant Microbe Interact. 19, 1062-1071. doi: 10.1094/MPMI-19-1062

Conrath, U., Pieterse, C. M., and Mauch-Mani, B. (2002). Priming in plant-pathogen interactions. Trends Plant Sci. 7, 210-216. doi: 10.1016/S1360-1385(02)02244-6

Goto, S., Fuyuko, S.-S., Suetsugu, M., Selvaraj, M., Hayashi, N., Yamazaki, M., et al. (in press). Development of disease-resistant rice by optimized expression of WRKY45. Plant Biotechnol. J. (in press).

Cui, X., and Luan, S. (2012). A new wave of hormone research: crosstalk mechanisms. Mol. Plant 5, 959-960. doi: 10.1093/mp/sss090

De Vleesschauwer, D., Gheysen, G., and Höfte, M. (2013). Hormone defense networking in rice: tales from a different world. Trends Plant Sci. 18, 555-565. doi: 10.1016/j.tplants.2013.07.002

Dean, J. V., Mohammed, L. A., and Fitzpatrick, T. (2005). The formation, vacuolar localization, and tonoplast transport of salicylic acid glucose conjugates in tobacco cell suspension cultures. Planta 221, 287-296. doi: 10.1007/s00425-004-1430-3

Delaney, T. P., Friedrich, L., and Ryals, J. A. (1995). Arabidopsis signal transduction mutant defective in chemically and biologically induced disease resistance. Proc. Natl. Acad. Sci. U.S.A. 92, 6602-6606. doi: 10.1073/pnas.92.14.6602 
Delteil, A., Zhang, J., Lessard, P., and Morel, J. B. (2010). Potential candidate genes for improving rice disease resistance. Rice 3, 56-71. doi: 10.1007/s12284-009-9035-x Despres, C., Chubak, C., Rochon, A., Clark, R., Bethune, T., Desveaux, D., etal. (2003). The Arabidopsis NPR1 disease resistance protein is a novel cofactor that confers redox regulation of DNA binding activity to the basic domain/leucine zipper transcription factor TGA1. Plant Cell 15, 2181-2191. doi: 10.1105/tpc.012849

Dodds, P. N., and Rathjen, J. P. (2010). Plant immunity: towards an integrated view of plant-pathogen interactions. Nat. Rev. Genet. 11, 539-548. doi: $10.1038 / \mathrm{nrg} 2812$

Dong, X. (2004). NPR1, all things considered. Curr. Opin. Plant Biol. 7, 547-552. doi: 10.1016/j.pbi.2004.07.005

Dowen, R. H., Pelizzola, M., Schmitz, R. J., Lister, R., Dowen, J. M., Nery, J. R., et al (2012). Widespread dynamic DNA methylation in response to biotic stress. Proc Natl. Acad. Sci. U.S.A. 109, E2183-E2191. doi: 10.1073/pnas.1209329109

Durrant, W. E., and Dong, X. (2004). Systemic acquired resistance. Annu. Rev. Phytopathol. 42, 185-209. doi: 10.1146/annurev.phyto.42.040803.140421

Endah, R., Beyene, G., Kiggundu, A., Van Den Berg, N., Schlüter, U., Kunert, K., et al. (2008). Elicitor and fusarium-induced expression of NPR1-like genes in banana. Plant Physiol. Biochem. 46, 1007-1014. doi: 10.1016/j.plaphy.2008.06.007

Fitzgerald, H. A., Canlas, P. E., Chern, M. S., and Ronald, P. C. (2005). Alteration of TGA factor activity in rice results in enhanced tolerance to Xanthomonas oryzae pv. oryzae. Plant J. 43, 335-347. doi: 10.1111/j.1365-313X.2005.02457.x

Fitzgerald, H. A., Chern, M. S., Navarre, R., and Ronald, P. C. (2004). Overexpression of (At)NPR1 in rice leads to a BTH- and environment-induced lesion-mimic/cell death phenotype. Mol. Plant Microbe Interact. 17, 140-151. doi: 10.1094/MPMI.2004.17.2.140

Fujii, K., and Hayano-Saito, Y. (2007). Genetics of durable resistance to rice panicle blast derived from an indica rice variety Modan. Jpn. J. Plant Sci. 1, 69-76.

Fujita, M., Fujita, Y., Noutoshi, Y., Takahashi, F., Narusaka, Y., Yamaguchi-Shinozaki, K., et al. (2006). Crosstalk between abiotic and biotic stress responses: a current view from the points of convergence in the stress signaling networks. Curr. Opin. Plant Biol. 9, 436-442. doi: 10.1016/j.pbi.2006.05.014

Gaffney, T., Friedrich, L., Vernooij, B., Negrotto, D., Nye, G., Uknes, S., et al. (1993). Requirement of salicylic acid for the induction of systemic acquired resistance. Science 261, 754-756. doi: 10.1126/science.261.5122.754

Garg, R., Tyagi, A. K., and Jain, M. (2012). Microarray analysis reveals overlapping and specific transcriptional responses to different plant hormones in rice. Plant Signal. Behav. 7, 951-956. doi: 10.4161/psb.20910

Gill, M. A., and Bonman, J. M. (1988). Effects of water deficit on rice blast. I. Influence of water deficit on components of resistance. J. Plant Prot. Trop. 5, 61-66.

Glazebrook, J. (2005). Contrasting mechanisms of defense against biotrophic and necrotrophic pathogens. Annu. Rev. Phytopathol. 43, 205-227. doi 10.1146/annurev.phyto.43.040204.135923

Gnanamanickam, S. S., Priyadarisini, V. B., Narayanan, N. N., Vasudevan, P., and Kavitha, S. (1999). An overview of bacterial blight disease of rice and strategies for its management. Curr. Sci. 77, 1435-1443.

Görlach, J., Volrath, S., Knauf-Beiter, G., Hengy, G., Beckhove, U., Kogel, K. H., et al. (1996). Benzothiadiazole, a novel class of inducers of systemic acquired resistance, activates gene expression and disease resistance in wheat. Plant Cell 8, 629-643. doi: 10.1105/tpc.8.4.629

Han, M., Ryu, H.-S., Kim, C.-Y., Park, D.-S., Ahn, Y.-K., and Jeon, J.-S. (2013). OsWRKY30 is a transcription activator that enhances rice resistance to the Xanthomonas oryzae pathovar oryzae. J. Plant Biol. 56, 258-265. doi: 10.1007/s12374-013-0160-0

Hayashi, N., Inoue, H., Kato, T., Funao, T., Shirota, M., Shimizu, T., et al (2010). Durable panicle blast-resistance gene Pb1 encodes an atypical CC-NBSLRR protein and was generated by acquiring a promoter through local genome duplication. Plant J. 64, 498-510. doi: 10.1111/j.1365-313X.2010.04348.x

Heidel, A. J., Clarke, J. D., Antonovics, J., and Dong, X. (2004). Fitness costs of mutations affecting the systemic acquired resistance pathway in Arabidopsis thaliana Genetics 168, 2197-2206. doi: 10.1534/genetics.104.032193

Heil, M., and Baldwin, I. T. (2002). Fitness costs of induced resistance: emerging experimental support for a slippery concept. Trends Plant Sci. 7, 61-67. doi: 10.1016/S1360-1385(01)02186-0

Heil, M., Hilpert, A., Kaiser, W., and Linsenmair, K. E. (2000). Reduced growth and seed set following chemical induction of pathogen defence: does systemic acquired resistance (SAR) incur allocation costs? J. Ecol. 88, 645-654. doi: 10.1046/j.1365-2745.2000.00479.x

Hu, H., Dai, M., Yao, J., Xiao, B., Li, X., Zhang, Q., et al. (2006). Overexpressing a NAM, ATAF, and CUC (NAC) transcription factor enhances drought resistance and salt tolerance in rice. Proc. Natl. Acad. Sci. U.S.A. 103, 12987-12992. doi: 10.1073/pnas.0604882103

Inoue, H., Hayashi, N., Matsushita, A., Liu, X., Nakayama, A., Sugano, S., et al. (2013). Blast resistance of CC-NB-LRR protein Pb1 is mediated by WRKY45 through protein-protein interaction. Proc. Natl. Acad. Sci. U.S.A. 110, 9577-9582. doi: $10.1073 /$ pnas.1222155110

Iwai, T., Seo, S., Mitsuhara, I., and Ohashi, Y. (2007). Probenazole-induced accumulation of salicylic acid confers resistance to Magnaporthe grisea in adult rice plants. Plant Cell Physiol. 48, 915-924. doi: 10.1093/pcp/pcm062

Iwata, M., Suzuki, Y., Watanabe, T., Mase, S., and Sekikawa, Y. (1980). Effect of probenazole on the activities related to the resistant reaction in rice plant. Ann Phytopathol. Soc. Jpn. 46, 297-306. doi: 10.3186/jjphytopath.46.297

Jaskiewicz, M., Conrath, U., and Peterhansel, C. (2011). Chromatin modification acts as a memory for systemic acquired resistance in the plant stress response. EMBO Rep. 12, 50-55. doi: 10.1038/embor.2010.186

Jiang, C. J., Shimono, M., Maeda, S., Inoue, H., Mori, M., Hasegawa, M., et al. (2009). Suppression of the rice fatty-acid desaturase gene OsSSI2 enhances resistance to blast and leaf blight diseases in rice. Mol. Plant Microbe Interact. 22, 820-829. doi: 10.1094/MPMI-22-7-0820

Jiang, C. J., Shimono, M., Sugano, S., Kojima, M., Liu, X., Inoue, H., et al. (2013). Cytokinins act synergistically with salicylic acid to activate defense gene expression in rice. Mol. Plant Microbe Interact. 26, 287-296. doi: 10.1094/MPMI-06-12-0152-R

Jiang, C.-J., Shimono, M., Sugano, S., Kojima, M., Yazawa, K., Yoshida, R., et al. (2010). Abscisic acid interacts antagonistically with salicylic acid signaling pathway in rice-Magnaporthe grisea interaction. Mol. Plant Microbe Interact. 23, 791-798. doi: 10.1094/MPMI-23-6-0791

Johnson, C., Boden, E., and Arias, J. (2003). Salicylic acid and NPR1 induce the recruitment of trans-activating TGA factors to a defense gene promoter in Arabidopsis. Plant Cell 15, 1846-1858. doi: 10.1105/tpc.012211

Jones, J. D., and Dangl, J. L. (2006). The plant immune system. Nature 444, 323-329. doi: 10.1038 /nature05286

Kahn, R. P., and Libby, J. L. (1958). The effect of environmental factors and plant ages on the infection of rice by the blast fungus, Pyricularia oryzae. Phytopathology $48,25-30$.

Kaneda, T., Taga, Y., Takai, R., Iwano, M., Matsui, H., Takayama, S., et al. (2009). The transcription factor OsNAC4 is a key positive regulator of plant hypersensitive cell death. EMBO J. 28, 926-936. doi: 10.1038/emboj.2009.39

Katz, V. A., Thulke, O. U., and Conrath, U. (1998). A benzothiadiazole primes parsley cells for augmented elicitation of defense responses. Plant Physiol. 117, 1333-1339. doi: 10.1104/pp.117.4.1333

Kauss, H., Theisinger-Hinkel, E., Mindermann, R., and Conrath, U. (1992) Dichloroisonicotinic and salicylic acid, inducers of systemic acquired resistance, enhance fungal elicitor responses in parsley cells. Plant J. 2, 655-660. doi: 10.1111/j.1365-313X.1992.tb00134.x

Khush, G. S. (2005). What it will take to feed 5.0 billion rice consumers in 2030 Plant Mol. Biol. 59, 1-6. doi: 10.1007/s11103-005-2159-5

Koga, H., Dohi, K., and Mori, M. (2004). Abscisic acid and low temperatures suppress the whole plant-specific resistance reaction of rice plants to the infection of Magnaporthe grisea. Physiol. Mol. Plant Pathol. 65, 3-9. doi: 10.1016/j.pmpp.2004.11.002

Lawton, K. A., Friedrich, L., Hunt, M., Weymann, K., Delaney, T., Kessmann, H., et al. (1996). Benzothiadiazole induces disease resistance in Arabidopsis by activation of the systemic acquired resistance signal transduction pathway. Plant J. 10, 71-82. doi: 10.1046/j.1365-313X.1996.10010071.x

Le Henanff, G., Heitz, T., Mestre, P., Mutterer, J., Walter, B., and Chong, J. (2009). Characterization of Vitis vinifera NPR1 homologs involved in the regulation of pathogenesis-related gene expression. BMC Plant Biol. 9:54. doi: 10.1186/14712229-9-54

Li, J., Brader, G., and Palva, E. T. (2004). The WRKY70 transcription factor: a node of convergence for jasmonate-mediated and salicylate-mediated signals in plant defense. Plant Cell 16, 319-331. doi: 10.1105/tpc.016980

Li, R., Afsheen, S., Xin, Z., Han, X., and Lou, Y. (2013). OsNPR1 negatively regulates herbivore-induced JA and ethylene signaling and plant resistance to 
a chewing herbivore in rice. Physiol. Plant. 147, 340-351. doi: 10.1111/j.13993054.2012.01666.x

Lipford, J. R., and Deshaies, R. J. (2003). Diverse roles for ubiquitin-dependent proteolysis in transcriptional activation. Nat. Cell Biol. 5, 845-850. doi: 10.1038/ncb1003-845

Liu, X., Li, F., Tang, J., Wang, W., Zhang, F., Wang, G., et al. (2012). Activation of the jasmonic acid pathway by depletion of the hydroperoxide lyase OsHPL3 reveals crosstalk between the HPL and AOS branches of the oxylipin pathway in rice. PLoS ONE 7:e50089. doi: 10.1371/journal.pone.0050089

Luna, E., Bruce, T. J., Roberts, M. R., Flors, V., and Ton, J. (2012). Nextgeneration systemic acquired resistance. Plant Physiol. 158, 844-853. doi: 10.1104/pp.111.187468

Makandar, R., Essig, J. S., Schapaugh, M. A., Trick, H. N., and Shah, J. (2006). Genetically engineered resistance to Fusarium head blight in wheat by expression of Arabidopsis NPR1. Mol. Plant Microbe Interact. 19, 123-129. doi: 10.1094/MPMI-19-0123

Malamy, J., Carr, J. P., Klessig, D. F., and Raskin, I. (1990). Salicylic acid: a likely endogenous signal in the resistance response of tobacco to viral infection. Science 250, 1002-1004. doi: 10.1126/science.250.4983.1002

Malamy, J., and Klessig, D. F. (1992). Salicylic-acid and plant-disease resistance. Plant J. 2, 643-654. doi: 10.1111/j.1365-313X.1992.tb00133.x

Malnoy, M., Jin, Q., Borejsza-Wysocka, E. E., He, S. Y., and Aldwinckle, H. S. (2007). Overexpression of the apple MPNPR1 gene confers increased disease resistance in Malus $\times$ domestica. Mol. Plant Microbe Interact. 20, 1568-1580. doi: 10.1094/MPMI-20-12-1568

March-Diaz, R., Garcia-Dominguez, M., Lozano-Juste, J., Leon, J., Florencio, F. J., and Reyes, J. C. (2008). Histone H2A.Z and homologues of components of the SWR1 complex are required to control immunity in Arabidopsis. Plant J. 53, 475-487. doi: 10.1111/j.1365-313X.2007.03361.x

Matsumoto, K. (1980). On the relationship between plant hormones and rice blast resistance. Ann. Phytopathol. Soc. Jpn. 46, 307-314. doi: 10.3186/jjphytopath. 46.307

Matsushita, A., Inoue, H., Goto, S., Nakayama, A., Sugano, S., Hayashi, N., et al. (2013). The nuclear ubiquitin proteasome degradation affects WRKY45 function in the rice defense program. Plant J. 73, 302-313. doi: 10.1111/tpj.12035

Matyssek, R., Agerer, R., Ernst, D., Munch, J. C., Osswald, W., Pretzsch, H., et al. (2005). The plant's capacity in regulating resource demand. Plant Biol. (Stuttg.) 7, 560-580. doi: 10.1055/s-2005-872981

Mauch-Mani, B., and Slusarenko, A. J. (1996). Production of salicylic acid precursors is a major function of phenylalanine ammonia-lyase in the resistance of Arabidopsis to Peronospora parasitica. Plant Cell 8, 203-212. doi: 10.1105/tpc.8.2.203

Métraux, J.-P., Ahl-Goy, P., Staub, T., Speich, J., Steinemann, A., Ryals, J., et al. (1991) "Induced resistance in cucumber in response to 2,6-dichloroisonicotinic acid and pathogens," in Advances in Molecular Genetics of Plant-Microbe Interactions, vol. 1, eds H. Hennecke and D. P. S. Verma (Dordrecht: Kluwer Academic Publishers) 432-439.

Métraux, J. P., Signer, H., Wyss-Benz, M., Gaudin, J., Ryals, J., Ward, E., et al. (1990). Increase in salicylic acid at the onset of systemic acquired resistance in cucumber. Science 250, 1004-1006. doi: 10.1126/science.250.4983.1004

Miah, G., Rafii, M. Y., Ismail, M. R., Puteh, A. B., Rahim, H. A., Asfaliza, R., et al. (2013). Blast resistance in rice: a review of conventional breeding to molecular approaches. Mol. Biol. Rep. 40, 2369-2388. doi: 10.1007/s11033-012-2318-0

Mou, Z., Fan, W., and Dong, X. (2003). Inducers of plant systemic acquired resistance regulate NPR1 function through redox changes. Cell 113, 935-944. doi 10.1016/S0092-8674(03)00429-X

Muratani, M., and Tansey, W. P. (2003). How the ubiquitin-proteasome system controls transcription. Nat. Rev. Mol. Cell Biol. 4, 192-201. doi: 10.1038/nrm1049

Nahar, K., Kyndt, T., Nzogela, Y. B., and Gheysen, G. (2012). Abscisic acid interacts antagonistically with classical defense pathways in rice-migratory nematode interaction. New Phytol. 196, 901-913. doi: 10.1111/j.1469-8137.2012.04310.x

Nakayama, A., Fukushima, S., Goto, S., Matsushita, A., Shimono, M., Sugano, S., et al. (2013). Genome-wide identification of WRKY45-regulated genes that mediate benzothiadiazole-induced defense responses in rice. BMC Plant Biol. 13:150. doi: 10.1186/1471-2229-13-150

Nawrath, C., and Metraux, J. P. (1999). Salicylic acid induction-deficient mutants of Arabidopsis express PR-2 and PR-5 and accumulate high levels of camalexin after pathogen inoculation. Plant Cell 11, 1393-1404. doi: 10.1105/tpc.11.8.1393
Nurnberger, T., Brunner, F., Kemmerling, B., and Piater, L. (2004). Innate immunity in plants and animals: striking similarities and obvious differences. Immunol. Rev. 198, 249-266. doi: 10.1111/j.0105-2896.2004.0119.x

Oerke, E. C., and Dehne, H. W. (2004). Safeguarding production-losses in major crops and the role of crop protection. Crop Prot. 23, 275-285. doi: 10.1016/j.cropro.2003.10.001

Ou, S. H. (1987). Rice Diseases. 2nd Edn. Slough: Commonwealth Mycological Institute.

Pasquer, F., Isidore, E., Zarn, J., and Keller, B. (2005). Specific patterns of changes in wheat gene expression after treatment with three antifungal compounds. Plant Mol. Biol. 57, 693-707. doi: 10.1007/s11103-005-1728-y

Pastor, V., Luna, E., Mauch-Mani, B., Ton, J., and Flors, V. (2013). Primed plants do not forget. Environ. Exp. Bot. 94, 46-56. doi: 10.1016/j.envexpbot.2012.02.013

Peng, X., Hu, Y., Tang, X., Zhou, P., Deng, X., Wang, H., et al. (2012). Constitutive expression of rice WRKY30 gene increases the endogenous jasmonic acid accumulation, $\mathrm{PR}$ gene expression and resistance to fungal pathogens in rice. Planta 236, 1485-1498. doi: 10.1007/s00425-012-1698-7

Peng, Y., Bartley, L. E., Chen, X., Dardick, C., Chern, M., Ruan, R., et al. (2008). OsWRKY62 is a negative regulator of basal and Xa21-mediated defense against Xanthomonas oryzae pv. oryzae in rice. Mol. Plant 1, 446-458. doi: $10.1093 / \mathrm{mp} / \mathrm{ssn} 024$

Pieterse, C. M., Van Der Does, D., Zamioudis, C., Leon-Reyes, A., and Van Wees, S. C. (2012). Hormonal modulation of plant immunity. Annu. Rev. Cell Dev. Biol. 28, 489-521. doi: 10.1146/annurev-cellbio-092910-154055

Qiu, D., Xiao, J., Ding, X., Xiong, M., Cai, M., Cao, Y., et al. (2007). OsWRKY13 mediates rice disease resistance by regulating defense-related genes in salicylateand jasmonate-dependent signaling. Mol. Plant Microbe Interact. 20, 492-499. doi: 10.1094/MPMI-20-5-0492

Qiu, D., Xiao, J., Xie, W., Cheng, H., Li, X., and Wang, S. (2009). Exploring transcriptional signalling mediated by OsWRKY13, a potential regulator of multiple physiological processes in rice. BMC Plant Biol. 9:74. doi: 10.1186/1471-2229-9-74

Qiu, D., Xiao, J., Xie, W., Liu, H., Li, X., Xiong, L., et al. (2008). Rice gene network inferred from expression profiling of plants overexpressing OsWRKY13, a positive regulator of disease resistance. Mol. Plant 1, 538-551. doi: 10.1093/mp/ssn012

Robert-Seilaniantz, A., Grant, M., and Jones, J. D. (2011). Hormone crosstalk in plant disease and defense: more than just jasmonate-salicylate antagonism. Annu. Rev. Phytopathol. 49, 317-343. doi: 10.1146/annurev-phyto-073009-114447

Saijo, Y., and Reimer-Michalski, E.-M. (2013). "Epigenetic control of plant immunity," in Epigenetic Memory and Control in Plants, eds G. Grafi and N. Ohad (Heidelberg: Springer), 57-76. doi: 10.1007/978-3-642-35227-0_4

Schwessinger, B., and Ronald, P. C. (2012). Plant innate immunity: perception of conserved microbial signatures. Annu. Rev. Plant Biol. 63, 451-482. doi: 10.1146/annurev-arplant-042811-105518

Seo, Y. S., Chern, M., Bartley, L. E., Han, M., Jung, K. H., Lee, I., et al. (2011). Towards establishment of a rice stress response interactome. PLoS Genet. 7:e1002020. doi: 10.1371/journal.pgen.1002020

Shah, J., Kachroo, P., Nandi, A., and Klessig, D. F. (2001). A recessive mutation in the Arabidopsis SSI2 gene confers SA- and NPR1-independent expression of PR genes and resistance against bacterial and oomycete pathogens. Plant J. 25, 563-574. doi: 10.1046/j.1365-313x.2001.00992.x

Sharma, R., De Vleesschauwer, D., Sharma, M. K., and Ronald, P. C. (2013). Recent advances in dissecting stress-regulatory crosstalk in rice. Mol. Plant 6, 250-260. doi: $10.1093 / \mathrm{mp} / \mathrm{sss} 147$

Shimono, M., Koga, H., Akagi, A., Hayashi, N., Goto, S., Sawada, M., et al. (2012). Rice WRKY45 plays important roles in fungal and bacterial disease resistance. Mol. Plant Pathol. 13, 83-94. doi: 10.1111/j.1364-3703.2011.00732.x

Shimono, M., Sugano, S., Nakayama, A., Jiang, C. J., Ono, K., Toki, S., et al. (2007). Rice WRKY45 plays a crucial role in benzothiadiazole-inducible blast resistance. Plant Cell 19, 2064-2076. doi: 10.1105/tpc.106.046250

Silverman, P., Seskar, M., Kanter, D., Schweizer, P., Metraux, J. P., and Raskin, I. (1995). Salicylic acid in rice: biosynthesis, conjugation, and possible role. Plant Physiol. 108, 633-639.

Song, J. T. (2006). Induction of a salicylic acid glucosyltransferase, AtSGT1, is an early disease response in Arabidopsis thaliana. Mol. Cells 22, 233-238.

Spoel, S. H., and Dong, X. (2012). How do plants achieve immunity? Defence without specialized immune cells. Nat. Rev. Immunol. 12, 89-100. doi: $10.1038 /$ nri3141 
Spoel, S. H., Koornneef, A., Claessens, S. M., Korzelius, J. P., Van Pelt, J. A., Mueller, M. J., et al. (2003). NPR1 modulates cross-talk between salicylate- and jasmonatedependent defense pathways through a novel function in the cytosol. Plant Cell 15, 760-770. doi: 10.1105/tpc.009159

Spoel, S. H., Mou, Z., Tada, Y., Spivey, N. W., Genschik, P., and Dong, X. (2009). Proteasome-mediated turnover of the transcription coactivator NPR1 plays dual roles in regulating plant immunity. Cell 137, 860-872. doi 10.1016/j.cell.2009.03.038

Sugano, S., Jiang, C.-J., Miyazawa, S.-I., Masumoto, C., Yazawa, K., Hayashi, N., et al. (2010). Role of OsNPR1 in rice defense program as revealed by genomewide expression analysis. Plant Mol. Biol. 74, 549-562. doi: 10.1007/s11103-0109695-3

Tada, Y., Spoel, S. H., Pajerowska-Mukhtar, K., Mou, Z., Song, J., Wang, C., et al. (2008). Plant immunity requires conformational changes of NPR1 via S-nitrosylation and thioredoxins. Science 321, 952-956. doi: 10.1126/science. 1156970

Takatsuji, H., and Jiang, C.-J. (2014). "Plant hormone crosstalks under biotic stresses," in Phytohormones: a Window to Metabolism, Signaling and Biotechnological Applications, eds L.-S. P. Tran and S. Pal (New York : Springer), 323-350.

Takatsuji, H., Jiang, C.-J., and Sugano, S. (2010). Salicylic acid signaling pathway in rice and the potential applications of its regulators. Jpn. Agric. Res. Q. 44 217-223. doi: 10.6090/jarq.44.217

Tao, Z., Liu, H., Qiu, D., Zhou, Y., Li, X., Xu, C., et al. (2009). A pair of allelic WRKY genes play opposite roles in rice-bacteria interactions. Plant Physiol. 151, 936-948. doi: 10.1104/pp.109.145623

Thaler, J. S., Humphrey, P. T., and Whiteman, N. K. (2012). Evolution of jasmonate and salicylate signal crosstalk. Trends Plant Sci. 17, 260-270. doi: 10.1016/j.tplants.2012.02.010

Thulke, O., and Conrath, U. (1998). Salicylic acid has a dual role in the activation of defence-related genes in parsley. Plant J. 14, 35-42. doi: 10.1046/j.1365313X.1998.00093.x

Tong, X., Qi, J., Zhu, X., Mao, B., Zeng, L., Wang, B., et al. (2012). The rice hydroperoxide lyase OsHPL3 functions in defense responses by modulating the oxylipin pathway. Plant J. 71, 763-775. doi: 10.1111/j.1365-313X.2012.05027.x

Tsuda, K., Sato, M., Stoddard, T., Glazebrook, J., and Katagiri, F. (2009). Network properties of robust immunity in plants. PLoS Genet. 5:e1000772. doi: 10.1371/journal.pgen.1000772

Ueno, Y., Yoshida, R., Kishi-Kaboshi, M., Matsushita, A., Jiang, C. J., Goto, S., et al. (2013). MAP kinases phosphorylate rice WRKY45. Plant Signal. Behav. 8, e24510. doi: $10.4161 /$ psb. 24510

Umemura, K., Satou, J., Iwata, M., Uozumi, N., Koga, J., Kawano, T., et al. (2009). Contribution of salicylic acid glucosyltransferase, OsSGT1, to chemically induced disease resistance in rice plants. Plant J. 57, 463-472. doi 10.1111/j.1365-313X.2008.03697.x

Uquillas, C., Letelier, I., Blanco, F., Jordana, X., and Holuigue, L. (2004). NPR1independent activation of immediate early salicylic acid-responsive genes in Arabidopsis. Mol. Plant Microbe Interact. 17, 34-42. doi: 10.1094/MPMI.2004.17.1.34

Walters, D. R., Mcroberts, N., and Fitt, B. D. (2008). Are green islands red herrings? Significance of green islands in plant interactions with pathogens and pests. Biol. Rev. Camb. Philos. Soc. 83, 79-102. doi: 10.1111/j.1469-185X.2007.00033.x

Wang, D., Amornsiripanitch, N., and Dong, X. (2006). A genomic approach to identify regulatory nodes in the transcriptional network of systemic acquired resistance in plants. PLoS Pathog. 2:e123. doi: 10.1371/journal.ppat.0020123

Weigel, R. R., Bauscher, C., Pfitzner, A. J., and Pfitzner, U. M. (2001). NIMIN-1, NIMIN-2 and NIMIN-3, members of a novel family of proteins from Arabidopsis that interact with NPR1/NIM1, a key regulator of systemic acquired resistance in plants. Plant Mol. Biol. 46, 143-160. doi: 10.1023/A:1010652620115

Weigel, R. R., Pfitzner, U. M., and Gatz, C. (2005). Interaction of NIMIN1 with NPR1 modulates PR gene expression in Arabidopsis. Plant Cell 17, 1279-1291. doi: $10.1105 /$ tpc.104.027441

Wildermuth, M. C., Dewdney, J., Wu, G., and Ausubel, F. M. (2001). Isochorismate synthase is required to synthesize salicylic acid for plant defence. Nature 414, 562-565. doi: 10.1038/35107108
Wu, Y., Zhang, D., Chu, J. Y., Boyle, P., Wang, Y., Brindle, I. D., et al. (2012). The Arabidopsis NPR1 protein is a receptor for the plant defense hormone salicylic acid. Cell Rep. 1, 639-647. doi: 10.1016/j.celrep.2012.05.008

Xiao, J., Cheng, H., Li, X., Xiao, J., Xu, C., and Wang, S. (2013). Rice WRKY13 regulates cross talk between abiotic and biotic stress signaling pathways by selective binding to different cis-elements. Plant Physiol. 163, 1868-1882. doi: 10.1104/pp.113.226019

Xu, J., Audenaert, K., Höfte, M., and De Vleesschauwer, D. (2013). Abscisic acid promotes susceptibility to the rice leaf blight pathogen pv by suppressing salicylic acid-mediated defenses. PLoS ONE 8:e67413. doi: 10.1371/journal.pone. 0067413

Yamada, S., Kano, A., Tamaoki, D., Miyamoto, A., Shishido, H., Miyoshi, S., et al. (2012). Involvement of OsJAZ8 in jasmonate-induced resistance to bacterial blight in rice. Plant Cell Physiol. 53, 2060-2072. doi: 10.1093/pcp/ pcs 145

Yamanouchi, U., Yano, M., Lin, H., Ashikari, M., and Yamada, K. (2002). A rice spotted leaf gene, Spl7, encodes a heat stress transcription factor protein. Proc. Natl. Acad. Sci. U.S.A. 99, 7530-7535. doi: 10.1073/pnas.112209199

Yang, Y., Qi, M., and Mei, C. (2004). Endogenous salicylic acid protects rice plants from oxidative damage caused by aging as well as biotic and abiotic stress. Plant J. 40, 909-919. doi: 10.1111/j.1365-313X.2004.02267.x

Yasuda, M., Ishikawa, A., Jikumaru, Y., Seki, M., Umezawa, T., Asami, T., et al. (2008). Antagonistic interaction between systemic acquired resistance and the abscisic acid-mediated abiotic stress response in Arabidopsis. Plant Cell 20, 1678-1692. doi: 10.1105/tpc.107.054296

Yazawa, K., Jiang, C.-J., Kojima, M., Sakakibara, H., and Takatsuji, H. (2012). Reduction of abscisic acid levels or inhibition of abscisic acid signaling in rice during the early phase of Magnaporthe oryzae infection decreases its susceptibility to the fungus. Physiol. Mol. Plant Pathol. 78, 1-7. doi: 10.1016/j.pmpp.2011.12.003

Yokotani, N., Sato, Y., Tanabe, S., Chujo, T., Shimizu, T., Okada, K., et al. (2013). WRKY76 is a rice transcriptional repressor playing opposite roles in blast disease resistance and cold stress tolerance. J. Exp. Bot. 64, 5085-5097. doi: $10.1093 /$ jxb/ert298

Yoshioka, K., Nakashita, H., Klessig, D. F., and Yamaguchi, I. (2001). Probenazole induces systemic acquired resistance in Arabidopsis with a novel type of action. Plant J. 25, 149-157. doi: 10.1046/j.1365-313x.2001.00952.x

Yuan, Y., Zhong, S., Li, Q., Zhu, Z., Lou, Y., Wang, L., et al. (2007). Functional analysis of rice NPR1-like genes reveals that OsNPR1/NH1 is the rice orthologue conferring disease resistance with enhanced herbivore susceptibility. Plant Biotechnol. J. 5, 313-324. doi: 10.1111/j.1467-7652.2007.00243.x

Zhang, Q. (2007). Strategies for developing green super rice. Proc. Natl. Acad. Sci. U.S.A. 104, 16402-16409. doi: 10.1073/pnas.0708013104

Zipfel, C. (2009). Early molecular events in PAMP-triggered immunity. Curr. Opin. Plant Biol. 12, 414-420. doi: 10.1016/j.pbi.2009.06.003

Conflict of Interest Statement: The Guest Associate Editor Seiichi Toki declares that, despite being affiliated to the same institution as the author, the review process was handled objectively and no conflict of interest exists. The author declares that the research was conducted in the absence of any commercial or financial relationships that could be construed as a potential conflict of interest.

Received: 28 August 2014; accepted: 23 October 2014; published online: 13 November 2014.

Citation: Takatsuji H (2014) Development of disease-resistant rice using regulatory components of induced disease resistance. Front. Plant Sci. 5:630. doi: 10.3389/fpls.2014.00630

This article was submitted to Plant Biotechnology, a section of the journal Frontiers in Plant Science.

Copyright (C) 2014 Takatsuji. This is an open-access article distributed under the terms of the Creative Commons Attribution License (CC BY). The use, distribution or reproduction in other forums is permitted, provided the original author(s) or licensor are credited and that the original publication in this journal is cited, in accordance with accepted academic practice. No use, distribution or reproduction is permitted which does not comply with these terms. 